\title{
Cutaneous squamous cell carcinoma in the lateral abdominal wall of local Libyan ewes
}

\author{
S.K. Tmumen ${ }^{1}$, S.A. Al-Azreg ${ }^{2}$, M.H. Abushhiwa ${ }^{1, *}$, M.A. Alkoly ${ }^{1}$, E.M. Bennour ${ }^{3}$ and S.R. Al-Attar ${ }^{2}$ \\ ${ }^{1}$ Department of Surgery and Theriogenology, Faculty of Veterinary Medicine, University of Tripoli, Tripoli, Libya \\ ${ }^{2}$ Department of Pathology and Clinical Pathology, Faculty of Veterinary Medicine, University of Tripoli, \\ Tripoli, Libya \\ ${ }^{3}$ Department of Internal Medicine, Faculty of Veterinary Medicine, University of Tripoli, Tripoli, Libya
}

\begin{abstract}
Gross and histopathological features of surgically excised squamous cell carcinomas (SCC) observed in thirteen local Libyan ewes were reported. The age of the ewes enrolled in the current study ranged from 2 to 3 years. The cases were admitted to private veterinary clinics in south-western region of Tripoli, Libya, during the period between July 2014 and October 2015. All lesions were located in the right and left lateral abdominal wall (caudo-ventrally) with a size range of 8 to $11 \mathrm{~cm}$ in diameter. The tumor masses have been removed by surgical excision. The histopathological examination of surgically excised masses has revealed the characteristic cell nests of SCC showing central keratinization and hyalinization with presence of apoptotic bodies, fattened keratinocytes, and a heavy interstitial infiltration of neutrophils and lymphocytes. The follow up of the cases showed no signs of tumor reoccurrence. In conclusion, SCC in Libyan sheep affects mainly the woolless areas and can be successfully removed by surgical excision.
\end{abstract}

Keywords: Histopathological findings, Lateral abdominal wall, Libyan ewes, Squamous cell carcinoma, Surgical excision.

\section{Introduction}

Tumors of skin and subcutaneous tissues are the most frequently recorded tumors in farm animal species (Tmumen, 1992; Hassanein and Mahmoud, 2009; Ahmed and Hassanein, 2012). Squamous Cell Carcinoma (SCC) is a malignant tumor of epidermal cells causing the differentiation of these cells to keratinocytes (Goldschmidt and Hendrick, 2002). SCC is the second most common skin tumor in farm animals. This type of tumor is mostly seen in aged animals, so that it is almost impossible to determine the incidence of SCC in farm animals as a large percentage of these animals slaughtered at an early age (Del Fava et al., 2001; Goldschmidt and Hendrick 2002; Valentine, 2004). The proposed etiologies for SCC include the prolonged exposure to sunlight and photosensitizingagents containing plants and the lack of skin pigmentation and hair (Valentine, 2004; Hassanein and Mahmoud, 2009). Additionally, the overexpression of p53 has been found to play an important role in the development of SCC in human and animals (Teifke and Löhr, 1996). Papilloma virus has also been mentioned as a possible cause of SCC in sheep (Del Fava et al., 2001).

In sheep, SCC has been reported in different breeds (Hassanein and Mahmoud, 2009; Ahmed and Hassanein, 2012; Najarnezhad and Aslani, 2012) and in various locations throughout the body (Foreyt et al., 1991; Ramadan et al., 1991; Mendez et al., 1997). In a large scale study investigating the skin tumors in fattailed sheep and goats in the Kingdom of Saudia Arabia by Ahmed and Hassanein (2012), it has been found that SCC was much more common in females than males. The locations of SCC in sheep included head, shoulder, back, abdomen, limbs and tail. SCC in the lumbar region in sheep was reported in only one ewe as an unusual site (Najarnezhad and Aslani, 2012).

Metastasis of SCC to local lymph nodes can occur after long time from its appearance and wide surgical excision has been found to be successful to treat SCC prior to spreading to surrounding tissues (Valentine, 2004).

The current study aimed to record and describe thirteen cases of cutaneous SCC in local Libyan ewes in southwestern Tripoli as well as the outcome of surgical excision of such lesions.

\section{Materials and Methods}

\section{Animals, history and clinical examination}

The present study was carried out on thirteen Libyan ewes of 2-3 years old age. These ewes were brought from different geographical localities within the southwestern area of Great Tripoli during the period from July 2014 to October 2015. Tumor masses of different sizes erupted since 3-5 months on the lateral abdominal wall. The case history has been taken and a general clinical examination has been performed. In addition, a special examination for the tumor mass location, size and nature of lesion have been performed. Then, the 
affected ewes were subjected to a surgical excision for tumor mass removal and for further diagnosis by histopathological examination.

\section{Surgical procedure}

Before the surgical intervention, animals were deprived of food for the period of $24 \mathrm{~h}$. The animal was sedated and a local anesthetic agent was infiltrated at the surgical site. An elliptical skin incision was performed and the tumor mass was excised gently with some healthy tissues by blunt dissection. Then, the surgical wound was closed using non-absorbable suture material. The suture was removed 8-12 days post operation. The tumor masses were finally submitted to histopathological examination. Most of the cases were followed up via clinic visits or phone contact with the owners.

\section{Histopathology examination}

For histopathological examination, five tissue specimens were fixed in $10 \%$ buffered formalin for later processing and examination. All histopathological procedures were performed according to Bancroft and Cook (1984). The tissue sections were stained with haematoxylin and eosin (H\&E) following the standard procedure. The stained tissue sections were examined under light Microscope (ZEISS, Germany). The degree of tumor differentiation was determined according to Goldschmidt and Hendrick (2002).

\section{Results}

\section{Clinical examination}

The clinical examination showed that all animals were in a good general condition with normal body temperature.

\section{SCC lesions description}

Grossly, the tumor masses were firm in consistency with different sizes $(8-11 \mathrm{~cm}$ in diameter) and shapes (Fig. 1). The tumors were located in the caudo-ventral part of the lateral abdominal wall (9 cases at the right side and 4 cases at the left side). The lesion was sometimes associated with exudation, ulceration, feted odor or hemorrhage and surrounded by inflammatory zone.

\section{Histopathological findings}

Five biopsies involving the skin and subcutaneous tissue of the abdominal wall were examined. Large irregular subcutaneous mass was extensively ulcerated and necrotized with hemorrhage. Microscopical examination of the biopsies in all cases revealed the characteristic (pathognomonic) cell nests of SCC showing central keratinization and hyalinization with the presence of apoptotic bodies, fattened keratinocytes, and a heavy interstitial infiltration of neutrophils and lymphocytes. The neutrophils and lymphocytes appeared in the sections as they were trying to invade the cell nests, while some has already invaded the centers of cell nests with phagocytic and lytic activities. Hydropic degeneration in some of the

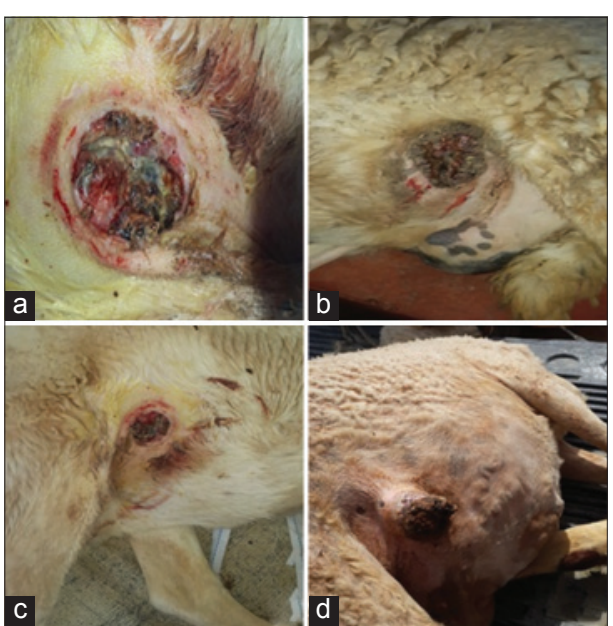

Fig. 1. Gross appearance and location of the SCC in Libyan sheep. (a) Almost round shaped SCC lesion at the left ventral abdominal wall with exudation and hemorrhage. (b) Unevenly shaped SCC lesion at the left ventral abdominal wall. (c) SCC lesion at the right ventral abdominal wall. (d) Projected fingerlike firm SCC lesion with ulceration and hemorrhage at the right ventral abdominal wall.

prickle cells surrounding the keratinized central layer has also been noticed. Numerous mitotic figures in all cases were also existed (Fig. 2a-f). Additionally, based on the histopathological findings, some carcinomas were well-differentiated and some of them were poorly differentiated.

\section{Prognosis of the surgical excision}

The follow up of the SCC cases showed no signs of tumor reoccurrence seven months after surgery. This indicated the effectiveness of the surgical intervention as an approach to treat such cases. Furthermore, there were no signs of local metastasis to the regional lymph nodes in any of the cases.

\section{Discussion}

Skin tumors, particularly SCC, has been extensively reported in the literature and stated by some authors as relative common skin tumor in sheep (Del Fava et al., 2001; Goldschmidt and Hendrick, 2002; Valentine, 2004; Hassanein and Mahmoud, 2009; Ahmed and Hassanein, 2012).

The current study reported the gross and microscopical characteristics of SCC masses found in the lateral abdominal wall of 13 local Libyan ewes aged between 2 and 3 years.

Cutaneous SCC has been reported to affect sheep in various sites in the hairless areas of the skin including head, shoulder, back, abdomen, limbs and tail (Ahmed and Hassanein, 2012), lumbar region (Najarnezhad and Aslani, 2012) and cervix and vagina (Ferrer et al., 2011). Interestingly, in all sheep recorded in our study, the tumor masses were at the same area, the lateral abdominal wall, and all animals were females which is the first report of such findings, as all findings 


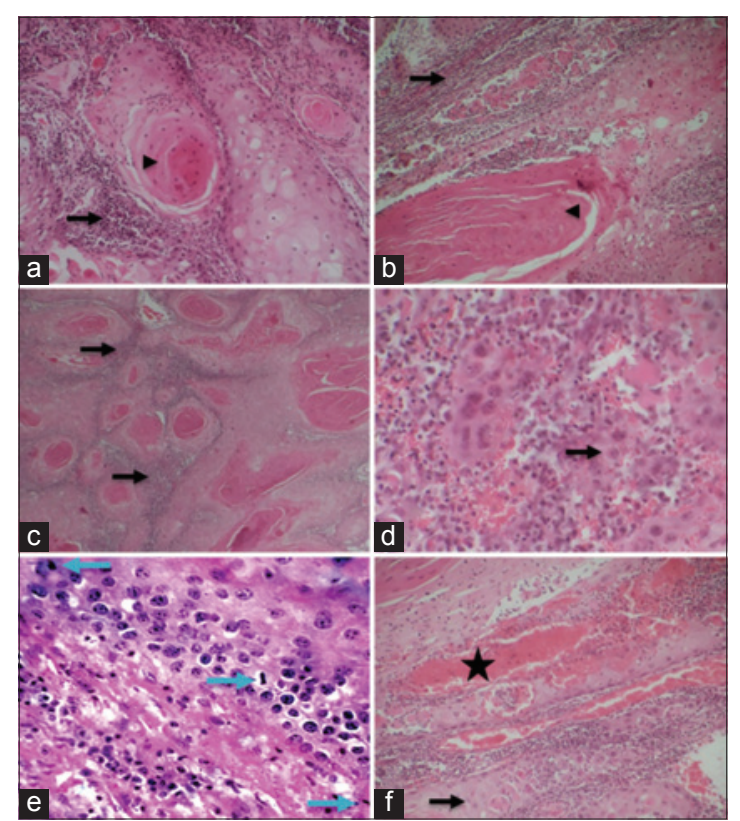

Fig. 2. Histopathological findings of the squamous cell carcinomas. (a\&b) Central keratinization and hyalinization (arrowheads) with heavy interstitial infiltration of inflammatory cells (neutrophils and lymphocytes) (arrows). (c) Aggregation of neutrophils around the outer layer of the cell nest. (d) Fattening and hyalinization of the central cell layer. (e) Neoplastic cells with mitotic figures (arrows). (f) Intense inflammatory reaction represented by dilated blood vessels (star) and huge aggregation of neutrophils and lymphocytes. The neutrophils invading some of the structures of cell nest specially the central keratinocytes (arrows). (H\&E stain: a\&b x100; c\&f x50; d\&e x400).

reported before showed that the tumor masses located in various parts throughout the body and recorded in both males and females. Although, in a recent report, ewes appeared to be more susceptible to SCC than rams (Ahmed and Hassanein, 2012).

Our findings are largely consistent with most of the previous reports in regard to the age of sheep affected with this kind of tumor. It has been found that the highest prevalence of SCC in sheep is from 4 to 6 years age and rarely recorded in sheep less than 4-year old (Mendez et al., 1997; Valentine, 2004; Ahmed and Hassanein, 2012). On the other hand, it has been stated that SCC is commonly reported in middle-aged to old sheep (Lloyd, 1961; Vandegraaff, 1976; Ladds and Entwistle, 1977; Riet-Correa et al., 1981; Lagadic et al., 1982; Scott, 2007). In the present study, the age of ewes affected with cutaneous SCC was between 2 and 3 years, which is supported by the findings of Scott (2007) and considered quite unique finding showing that this tumor can occur in younger age.

The underline cause of skin tumor is still unclear in general. However, several predisposing factors are believed to play a role in causing such tumors. One of these factors is the long exposure to sunlight and ultraviolet radiation (Valentine, 2004; Ahmed and Hassanein, 2012). Based on the geographical location of the ewes enrolled in the present study, the long exposure to radiation is likely to be the predisposing factor. Secondarily, the area of the lateral ventral abdomen is very susceptible to irritation by rough ground which might be another reason for having the tumor masses in this area instead of other predicted sites reported in literature.

\section{Conclusion}

We could conclude that the local Libyan ewes could be affected with SCC. The tumor affects mainly the right and left lateral abdominal woolless skin. The recorded cases were all females. Histopathological examination of the tumor biopsies revealed the pathognomonic cell nests of SCC. We could also conclude that surgical excision is an efficient treatment of non metastatized or infiltrated SCC without recurrence for several months. Further studies are required to investigate the prevalence of this skin tumor in Libyan sheep as well as its predisposing factors.

\section{Acknowledgment}

The authors would like to thank Turkia Aduma and Asma Al-Hammali, the technicians at the Pathology and Clinical Pathology Laboratory, Faculty of Veterinary Medicine, University of Tripoli, for their kindness and technical assistance.

\section{Conflict of interest}

For the present work the authors received no financial support and there is no conflict of interest.

\section{References}

Ahmed, A.F. and Hassanein, K.M.A. 2012. Ovine and caprine cutaneous and ocular neoplasms. Small Rum. Res. 106, 189-200.

Bancroft, J.D. and Cook, H.C. 1984. Manual of Histological Techniques. Churchill Livingstone, Edinburgh, London, Melbourne, New York.

Del Fava, C., Verissimo, C.J., Rodrigues, C.F.C., Cunha, E.A., Ueda, M., Maiorka, P.C. and Angelino, D.J.L. 2001. Occurrence of squamous cell carcinoma in sheep from a farm in Sao Paulo state, Brazil. Arquivo do Instituto de Biologia de Sao Paulo 68(1), 35-40.

Ferrer, L.M., Lacasta, D., Ramos, J.J., Jalón, J.A., Ruiz De Arcaute, M. and Conde, T. 2011. Squamous cell carcinoma of the vagaina and cervix in sheep- Case report. Acta Vet. Hung. 59, 123-127.

Foreyt, W.J., Hullinger, G. and A.Leathers, C.W. 1991. Squamous Cell Carcinoma in a Free-ranging Bighorn Sheep (Ovis Canadensis californiana). J. Wildl. Dis. 27, 518-520.

Goldschmidt, M.H. and Hendrick, M.J. 2002. Tumors of the skin and soft tissues. Tumors in Domestic 
Animals. $4^{\text {th }}$ ed. Iowa State University, pp: 105-107.

Hassanein, K.M.A. and Mahmoud, A.Z. 2009. Pathological studies on tumor incidence in farm animals. Alex. J. Vet. Sci. 28, 105-117.

Ladds, P.W. and Entwistle, K.W. 1977. Observations on squamous cell carcinomas of sheep in Queensland, Australia. Br. J. Cancer 35, 110-114.

Lagadic, M., Wyers, M., Mialot, J.P., ParodI, A.L. 1982. Observation d'une enzootie de cancers de la vulve chez la brebis. Zentralblatt für Veterinärmedizin Reihe A 29, 123-135.

Lloyd, L.C. 1961. Epithelial tumors of the skin of sheep. Br. J. Cancer 15, 780-789.

Mendez, A., Perez, J., Ruiz-Villamor, E., Garcia, R., Martin,M.P.andMozos,E. 1997. Clinicopathological study of an outbreak of squamous cell carcinoma in sheep. Vet. Rec. 23, 597-600.

Najarnezhad, V. and Aslani, M. R. 2012. Unusual case of cutaneous squamous cell carcinoma in an ewe. Iranian J. Vet. Sci. Technol. 4, 49-53.

Ramadan, R.O., Gameel, A.A. and El Hassan, A.M.
1991. Squamous cell carcinoma in sheep in Saudi Arabia. Rev. Elev. Med. Vet. Pays. Trop. 44, 23-26.

Riet-Correa, F., Cassal, A.B., Scarsi, R.M., Schild, A.L. and Mendez, M.C. 1981. Carcinomas Epidermóides em ovinos em um estabelecimento do Rio Grande do Sul. Pesq. Vet. Bras. 1, 65-68.

Scott, R.P. 2007. The skin. In. Scott, R.P. Sheep Medicine. Manson Publication Ltd. The Veterinary Press, pp: 240-264.

Teifke, J.P. and Löhr, C.V. 1996. Immunohistochemical detection of P53 over expression in paraffin waxembedded squamous cell carcinomas of cattle, horses, cat and dogs. J. Comp. Pathol. 114, 205-210.

Tmumen, S.K. 1992. Surgical swelling in farm animals. M.V.Sc. Thesis. University of Tripoli. Tripoli, Libya.

Valentine, B.A. 2004. Neoplasia. In: Farm animal surgery. Saunders. Fubini, S.L. and Ducharme, N.G. $1^{\text {st }}$ ed. St Louis: Philadelphia: Saunders, pp: 23-44.

Vandegraaff, R. 1976. Squamous Cell Carcinoma of the Vulva in Merino Sheep. Aust. Vet. J. 52, 21-23. 